\title{
Anthropocentric and non-anthropocentric values as the basis of the new sustainable paradigm in architecture
}

\author{
M. J. González-Díaz \& J. García-Navarro \\ Technical University of Madrid, Spain
}

\begin{abstract}
Sustainability, as a new concept, has been adopted recently in the world of architecture, related to new technical utilities and new assessment environmental methods. At the same time, several eco-logics have been developed, according to a new approach from the world of energy, resources and health. After that, economical and social items have been summed up. From an aesthetical and expressive point of view, the architecture based in this new paradigm has not developed a new common language yet, which is still diverse, confused and non identifiable, but the trend in the future will establish new formal and coherent initiatives.

Eventually, all activities related to the world of architecture and construction are creating a holistic approach from an environmental viewpoint, which will be a really important matter for the human habitat in the future, according to the actual trend. The economics and social items related to architecture are showing that the environmental conscience must be spread not only to market and economical diplomacy, but to education, participation, and ethics too. The approach, then, is finally global, holistic and focused on values.

This scenario rooted to values means that the environmental awareness will be placed in a very significant position, in opposition to the last age, in which the technical pattern was one of the predominant, overestimated values. Hazards and impacts from Human activities over Nature are now essentially analyzed in every discipline, including construction and architecture. That means that what is really changing in the construction world is not only science or technology. What are changing are the values, which turned up from the sense of man as the centre of the universe to Nature in a first place, in harmony with nonanthropocentric values. This conviction can help to address the new focuses for
\end{abstract}


new research and action plans to continue in analyzing the new paradigm of sustainability.

Keywords: sustainable architecture, ethics, vernacular.

\section{Introduction}

Architecture's and architects' interest for the ecological has been in continuous development and on the rise, despite its staggering steps forward and backward. These interests have not come spontaneously: their history lies both in the field of architecture and philosophy, and by studying these we can deduce its evolution. On this history we can cite some of its main thinkers:

- Very active and committed writers and naturalists such as Thoreau, Elliot, and later on Leopold, Carson and others who have shown us the path towards an admiration and respect of nature (mother earth) in line with their consideration of indigenous people who were capable of maintaining a relationship of adaptation to the nature in which they lived. They had a strong influence on alternative architectural movements of the sixties, with a desire for a new lifestyle closer to nature, a rejection of an anti-solidarity consumption based economic system, and a desire to form part of the space in which they inhabit. The self-sufficiency programmed by the Vales [1] takes on both the desires for autonomy and that unconscious return to a more vernacular architecture that represents a union with the land.

- The awareness and respect for all cultures' vernacular architecture. Also popularly known as "architecture without architects," or "non-pedigree architecture" by Rudofsky [2] in that beautiful exhibit and book he successfully presented in the sixties, this architecture represented and had many of those attributes that these movements were looking for. In Europe, specifically in Spain, the interest for a "typical" construction, as it once was called, was the focus of admiration from Torres Balbás [3], Lampérez [4], Calzada and Fletcher [5] and Bassegoda in the first third of the $20^{\text {th }}$ century, and later on by GarcíaMercadal [6], Feduchi [7], Flores [8] and Fisac [9] when it began to fade. The agony of this simple architecture began with industrialization. While its interest rose and was deemed worthy of study, this architecture would die, without any claims, perfectly adapted to the climate and needs of its occupants. This architecture (until then it had not been considered architecture, but only local buildings), synthesized many desirable characteristics lost since industrialization and which could be aim of a new current review. Vernacular architecture is essentially characterized by its adaptation to the existing conditions in preindustrial societies. That's why it has been tied to self-sufficiency, since it used the resources available in the area, always limited, adapting its comfort levels to the locally available resource's optimal performance.

- A comparative discussion between the conditions of vernacular and postindustrial architecture. While vernacular architecture prioritized existing resources over the desired service, industrial and post-industrial architecture prioritized the service offered over the available resources. Here there is no adaptation to the surrounding conditions or resources, which are considered 
unlimited and always at humanity's disposal. The comfort level is independent of the external conditions and is assured via the use of technology based on energy resources, however far they may be, or however expensive or costly its use may be, according to González et al. [10].

- The various energy crises uncovered how fragile our situation is from an economic point of view. From this conceptual and ethical point of view, movements like Deep Ecology [11] synthesized reflection and favored a philosophy where international studies and initiatives on climate change strengthened and gave way to a new perspective. This movement (Naess, Gary Snyder, and Bill Devall) promulgated a deep reflection on our way of life, including a severe critique on an economic system based on property and the abuse of resources, foreign to the environment and self-destructive. Architectural technology developed favoring this alienation from nature. The existence of cheap and easily accessible fuel made it easy to design climate controls in buildings, indifferent of the exterior conditions: whatever the surroundings, there is a technical solution to ensure conditions of comfort.

- A strong population increase, especially in cities. In 200-300 years we have gone from being a predominantly vernacular architecture society, adapted to the external conditions, to gradually being a more urban and technological society: between 1950 and 2011 the urban population has increased almost fivefold. The reasonable and slow evolution of vernacular architecture's adaptation could not have been done without such extreme and unequal growth in riches and resources.

\section{Various architectural approaches}

Before this panorama, there have been many reactions and approaches that have powerfully affected the architectural world.

\subsection{The creative approach}

From various points of view, apparently foreign, there are various trains of thought with their corresponding architectural expressions. Ecological architecture, green or bioclimatic, healthy, bio-architecture, etc, are the various names of a very similar concept, mixed, undefined, that are gradually confirming themselves and obtaining their own place within the architectural and constructive world, placing themselves in their own field within a formal and informal world of techniques (high-tech/low-tech), participation (the vernacular /industrialization), the focus on resource use (reduced consumption/efficiency), the geopolitics of resources (solidarity/self-reliance), etc.

In 2001 Guy and Farmer [12] described six different points of view or ecologics that could be summarized as the following: eco-technology (priority on technology based solutions, like the work of Norman Foster, Ken Yeang, Renzo Piano, Richard Rogers, etc); eco-centric (in search of a building's autonomy in a world in harmony with nature, like the Vales, Papanek, Myke Reynold); ecoaesthetic (emphasis on individual creativity, in new design theories -including 
the chaos theory, like Gehry and Calatrava); eco-cultural (proposing a strong support of genius-loci and on the local reaction to international imposition, like Glenn Murcutt, Hassan Fatty); eco-medical (prioritizing health matters in construction, like bio-habitat, bio-architecture, etc); and eco-social (fomenting community harmony and participation politics, like the work of Peter Hubner, Lucien Kroll, and Ralph Erskine.

A decade later, some of these logics have disappeared, while their development has equalized some of the differences that identified them. For example, their preoccupation with energy has equally reached all of them, despite their original differences. The selection of materials and their value relative to the resources used is another of the common elements, despite the differences in priorities and criteria. Water is valued as a scarce resource in many of them. The radical differences of the origins of these "eco-logics" are decreasing, if not vanished. Some social aspects, like the emphasis on health in the buildings' users and construction workers are already part of the good practices, despite having a very different value within these eco-logics. In summary, many of the premises that at one time were considered part of an alternative movement have now become common practice.

\subsection{The institutional approach}

The institutions formalized the ecological problems well into the seventies. The list of reports and above all, the creation of commissions show an incessant expansion on the topics, on a large to small scale. From their interest in the lack of food for all the inhabitants of the planet (the Meadows report), to the many reports on climate problems produced by the IPCC (Intergovernmental Panel on Climate Change), by the World Meteorological Organisation and the United Nations' Programs for the Environment, ICLEI, C40, Climate Alliance, etc.

These institutions have created detailed reports on the impact of climate change on the increase in poverty. On 2011, the evidence of the changes produced by climate change is no longer doubtable, and they are detailed showing how their affects will be devastating on a wide range of sectors (human health, agriculture, human settlements, natural ecosystems, biodiversity). While its solutions may only be confronted with the detailed study of the contribution from a variety of human activities (industry, transportation, tourism, construction, etc.) to this climate change. This involves an expansion of the topics involved, since they are no longer technical - environmental, but now extending on to the social, cultural and ethical fields [13]. Architecture and construction participate in all of this, and are included in this general view, while these topics affect them in their technical, industrial, social and artistic aspects.

This is how it has reached the building sector, through its high contribution to energy consumption and $\mathrm{CO}_{2}$ emissions. But they are also studying the contribution of construction on water consumption, the emission of heavy metals into the atmosphere, etc. Cities are an important focus of study, not only for having a growing amount of inhabitants, but for being the nodes in which the management of human needs is more accessible, and therefore also the 
management of the environmental impacts, and arriving at the existence of local programs like Agenda 21.

There are specific documents that directly affect architecture and are expressly aimed at it, in all fields. The discussion on the materials used in construction started by demanding the repeal of CFC, asbestos, etc. [14]. In terms of energy, it started by reducing the energy needs, followed by promoting renewable energies, followed by promoting the creation of buildings that produced energy, finally anticipating that buildings themselves must produce their energy. Recycling of waste from construction, the use of recycled goods in buildings, water management... have been all gradually added.

\subsection{The regulatory approach}

Private and semi-private initiatives with the help of institutions and state research centers have contributed to these new construction panoramas. They have focused their activity in reducing the environmental impact on construction in general, within the current productive system. With this they are looking for processes that have less of an impact, always maintaining as reference the activity as it has always been done to that point. The international regulatory organisms CEN [15], AENOR [16], and others like iiSBE [17], CSTB [18], perform a task that analyses production, manufacturing and construction in all industrial aspects, supported by methods like lifespan analyses. The procedures are produced at different scales: buildings (environmental impact evaluation methods on buildings, GBTool, LEED, VERDE, etc); the product or the material (EDP).

Despite the different scales, all of these methods are based on a similar principle and methods that all have one common purpose, which can be summarized as:

"The green building movement aims to reduce resource and energy consumption, increases the use of renewable energy, minimize environmental degradation and the production of waste, and maximize occupant health and comfort.... The economic, social and environmental benefits of sustainable structure are numerous, and the increased construction and use of these buildings is a key component in maintaining the health of this planet" [19].

Notice the end of this quote. They have directly related constructive activities with "the planet's health," a holistic term in which the planet is an object to be valued.

The procedure has been expanded on. The development of these criteria, merely quantitative, scientific up to a point, have clearly gone through a process. The merely environmental point of view was annexed by the economical: not just any cost is considered acceptable. And again, another more: the social aspects must complement the complexity of the process, for which the material, the product or the building must be satisfactory. Throughout this process a term has been added: "sustainable." This term indicates that for any production to be 
maintained in time it must duly comply with the following triad: environmental, economic and social factors. Even though this latter element is not as developed as the former two, the catalogue of interests has been expanded on, according to Feirer [20], from the merely technical towards the fields that affect humanity. Finally, the planet is the element to preserve, and therefore the planet has become the subject of the action.

\section{Converging elements in the various approaches}

All of these "approaches" lead towards a similar goal. The different architectural eco-logics are closing in on each other: we can no longer easily allow an uncontrolled waste of energy and an unconscious use or remain ignorant of the environment's characteristics in materials or resources in general. Bioclimatic architecture, based on the study of vernacular architecture, has become the formal and spatial base to support a technology that achieves this zero-energy consumption, whether with a high-tech or low-tech building. The international initiatives look for buildings to not over consume energy, but to produce energy, to exploit few resources, to manage water properly, but to also provide humanistic aspects beyond merely technical, disseminating a message of complexity. The regulatory tools expand their domain towards social aspects besides that of the environmental and economic. To these aspects we can add a popular consciousness that now begins to develop, and that values the importance of simple, specific gestures like recycling waste, the use of public transport, etc. that is, the citizens collaboration that raises environmental consciousness in fundamental topics.

All of these approaches do converge. These are philosophies that meet and approach each other. At the base of these philosophies is a practical evidence that the aforementioned foretellers (Thoreau, Leopold, Naess...) proclaimed some time ago. Nature is the key element that has been object of a new perception, even though it has not been explicitly named (yet). The concept of sustainability implicitly includes a representation of the world inhabited by humanity while being a part of nature. This, which was something obvious for whoever lived in permanent contact with nature, like pre-industrialized people, was secondary or even ignored later on. But the value of some vernacular elements, the drift away from technical aspects, regulations and creativity all blend together to find common ground, indicating that something is changing.

The increase in ecology's domain also indicates a progressive change in mentality. We can use the metaphor of a path in permanent progress that starts with environmental aspects, then economic, followed by social aspects, such as those affecting health and the well-being of everybody participating in buildings. Besides these, we must also include cultural aspects that expand the limits of solidarity towards all inhabitants of the planet. This criterion already exists implicitly and is seen more and more. The problem of ecology cannot be understood without expanding the limits of social consciousness: the relationship between limited resources, or better yet, the extraction of resources from a specific geographical area, within the current military and geo-economic tensions 
cannot be ignored. The dependence of richer countries on other countries' resources (oil, coltan, uranium, water...) intermingles with enormous differences between them. It is common knowledge that not all countries contribute the same way to environmental problems, specifically global warming. Developing countries only generate $25 \%$ of the emissions per capita of the developed countries, while they are the most affected by natural disasters instigated by climate change. Architecture, both as an industry of construction and as an activity that studies and creates the space humanity inhabits, is not unfamiliar with this situation.

Again using the path metaphor, this drift can be interpreted as a change in values. These aforementioned approaches and initiatives are corroborating on a basic conclusion, already previously intuited wisely in other cultures. We belong to nature. This concept of including our world in another superior order is not always present. Norman Crowe asks Is the City Natural? [21] when reflecting on the emerging and disproportionate growth of the city and its way of life. What we understand in our collective unconscious is surely the idea of a world custommade for humanity, and

That "idea" continues to guide how we shape our world today and how we change nature to accommodate the presence of our world within it.

Humanity has created its habitat in accordance with its needs. Our ancestors were familiar with natural phenomena, the movement of the sun, the seasons, etc. Then continuous development and progress has eliminated the sensation and sensibility towards nature from which we came. Human beings can develop their whole lives within buildings with climate control, almost completely eliminating their connection to the seasons and atmospheric conditions. They may use all sorts of vehicles to cross any distance in a way that their perception of space is also modified and void. Post-industrial architecture has participated in this disconnection with an excessive confidence in technique and becoming part of the economic model of consumption. All previous approximations argue towards this critique and reflection:

"Nearly gone are the evolutionary processes that once corrected our mistakes and ensured that our architecture would continue to accommodate our spiritual and psychological needs. We need to pause and look back, to see where we have come from to apprehend where we might be going" [21, p. 234].

\section{Conclusions}

A prolongation of this trend seen in all approaches may lead us towards new conclusions. Nature has been considered in a post-industrial perspective as an instrumental value, at the service of mankind's needs. However, there are many symptoms that change is coming. The Earth Charter [22], open in 2000, is a programmed, consensual and collaborative text that may have been written by 
19th century idealists, since its content is not too far off from the ideas of Thoreau, the philosophies of the aboriginal Indians and their feelings towards the Earth they live in, as well as those of pacifists like Gandhi. There has been a progressive transformation that has been introducing variety into the official agendas of the formal world, because of need, until reaching the conclusion that were already an integral part of other cultures, and what at one time was revolutionary and alternative, is now official.

Finally, we have come to place the limit of the environmental consciousness in Nature, in capital letters, complete, and in all its grandness. The focus is comprehensive. What must be changed are not partial elements. Like the domino effect, certain elements have led to others, and from the first concerns (the effects of the expanding holes in the ozone layer, climate change, or any other impact) we have reached a real and holistic approach to the problem, going through many intermediate steps. This is not about improving one element or another; it's about the conviction that without knowing how to be in nature, without "dwelling" in the sense that Heidegger describes as "Building, dwelling, thinking" [23], without reaching the origin of the problem, little can be done.

The link between personal attitudes and their repercussion in any other part of the planet is an ethical reason. When in 1996 Karsten Harries studied the meaning of ethics in architecture in "The Ethical Function of Architecture" [24], ecology is not discussed explicitly in any of its chapters. However, by analyzing dwelling in the Heideggerian sense, he arrives at Rudofsky's thoughts on interpretation and possibilities of the vernacular in the industrialized world. Harries introduces the contradictory idea of architecture without architects (nonpedigreed/pedigreed architecture), since it makes up part of the tensions in architecture, much like representation and signifier. Today the relationship between architecture and ethics could not be studied without analyzing its degree of connection with the paradigm of sustainability.

Architecture reflects this point of reflection. The interest in rehabilitating existing heritage buildings, the transformation of cult architecture, the universal reference to energy and the expansion of environmental topics and the generalization of sustainability as a criteria are objective data. All of these are symptoms of a paradigm shift in which the centre is no longer in resolving humanity's needs (sometimes created with self-seeking interests) without resolving them within another main and greater system, such as nature. There is a social conscious based on the knowledge of connecting immediate, specific and personal activity (reducing consumption, using renewable energy, the impact on materials, waste, water...) with the problems of the planet in general. What happens in an apparently light architectural action has repercussions in another apparently remote place. For example, the use of one material or other may affect the health of the building's user, but there is enough information to know that the environmental impact embedded in its production may also affect the health of the inhabitant in another part of the world, since climate's evolution and its phenomena do not recognize borders.

Humanity and its needs is no longer the measure and centre of all things (anthropocentrism) and we are experiencing a paradigm shift in which the new 
subject of study is the planet, the environment, or whatever it is called. There is a change in values: humanity is no longer the subject; now Nature is. What we must conserve is the planet's condition and its internal relations. Post-industrial humanity's relationship with the environment has begun to change and accept the people who were able to survive because of a respectful relationship with nature. If the human species wants to survive it cannot have a power relationship with nature (the planet's resources are at the service of humanity), or a symbiotic one (both obtain the benefits of their relation), but a dependent one (in a potential change in climate, humanity would end up losing). If humanity wants to recuperate its ethic right, anthropocentrism must be rejected. The current process of architecture within what we have called the "sustainability paradigm" may be interpreted as an adoption of this transformation.

\section{References}

[1] Vale, B. Vale, R. The Autonomous House. New York, N.Y. Universe Books: New York, 1975.

[2] Rudofsky, B. Architecture without Architects: A Short Introduction to Non-pedigreed Architecture. Museum of Modern Art: New York, 1964.

[3] Torres-Balbás, L. La vivienda popular en España, Folklore y Costumbres de España, tomo III, Editorial Alberto Martín: Barcelona, 1934.

[4] Lampérez, V. Arquitectura civil española de los siglos I al XVIII.: Arquitectura privada. Ed. Giner: Madrid, 1993.

[5] Calzada, A., Fletcher, B. A history of architecture on the comparative method. Historia de la arquitectura en España Ed. Canosa: Barcelona, 1931.

[6] García-Mercadal, F. La casa popular en España. Ed. Espasa Calp: Madrid, 1930.

[7] Feducchi, L. Itinerarios de arquitectura popular. Ed. Blume: Barcelona, 1974.

[8] Flores, C. Arquitectura popular española. Ed. Aguilar: Madrid, 1986.

[9] Fisac, M. La arquitectura popular española y su valor ante la arquitectura del futuro. Ed. Rialp: Madrid, 1952.

[10] González M.J, García-Navarro J, Dorst M. The impossible myth of the vernacular city as a paradigm for optimizing resources. Proceedings, Sustainable Building SB08MED: Athens, 2008.

[11] Devall, B. The Deep Ecology Movement. 20 Nat. Resources Journal. 299, 1980.

[12] Guy, S. Farmer, G. Reinterpreting Sustainable Architecture: The Place of Technology. Journal of Architectural Education, 54 (3), pp 140-148, Feb 2001.

[13] The critical decade. Climate science, risk and responses. Climate Commission Secretariat. Australia 2011.

[14] Council Directive of 27 July 1976 on the approximation of the laws, regulations and administrative provisions of the Member States relating to 
restrictions on the marketing and use of certain dangerous substances and preparations (76/769/EEC).

[15] International Standardization for Sustainable Construction CEN/TC 350. www.cen.eu

[16] Asociación Española de Normalización y Certificación (AENOR) AEN/CTN 198/SC 1 Sostenibilidad de la Construcción. www.aenor.es

[17] iiSBE, International Initiative for a Sustainable Built Environment. www.iisbe.org

[18] CSTB Centre Scientifique et Technique du Bâtiment. www.cstb.fr

[19] Sangster, W. Benchmark Study on Green Buildings: Current Policies and Practices in Leading Green Building Nations. Industry Canada. Energy and Environmental Industries Branch. 2006.

[20] Feirer, L. Sustainability indicators in buildings. Identifying Key performance Indicators. http://www.iisbe.org/. 2011.

[21] Crowe, N. Nature and the idea of a man-made world. MIT Press: Massachusetts, 1995.

[22] The Earth Charter, http://www.earthcharterinaction.org/content/

[23] Heidegger, M. Buildings Dwelling Thinking. Martin Heidegger Works. Ed. Perennial Library: New York, 1975.

[24] Harries, K. The Ethical Function of Architecture. MIT Press: Massachusetts, 1997. 